\title{
Regional science in a resource-constrained world
}

\author{
Matthias Ruth ${ }^{1}$
}

Received: 27 February 2018 / Accepted: 30 August 2018 / Published online: 17 September 2018

(c) Springer-Verlag GmbH Germany, part of Springer Nature 2018

\begin{abstract}
This paper presents challenges to mainstream regional science that stem from the fact that regional economies are subsumed within larger social, economic and environmental systems. The constraints imposed by these systems are systematically overlooked or misidentified. The challenges that arise for regional science are of conceptual, methodological and empirical nature and have far-reaching implications for the uses and usefulness of regional science analysis in support of investment and policy making. The paper attends to both the challenges and ways they can be overcome.
\end{abstract}

Keywords Resource constraints · Optimality · Regional development · Regional science

\section{The power of the region}

Regional science has made many invaluable contributions to the understanding of social and economic dynamics at finer scales than what we typically find in national analyses. The value of these contributions comes from three key features. First, it is often the micro-phenomena observed at specific locations that lead to an emergence of the macro-outcomes to which national policy tends to react. For example, regional economies can serve as the drivers for national economic change, as well as migration that then generate the macro-patterns associated with business cycles and broader social outcomes.

Second, because investment and policy making take place at the level of individual communities or firms, for example, it is at these finer scales where the impacts of

This paper is a synopsis of my Presidential Address to the Western Regional Science Association, delivered on February 13, 2018 in Pasadena, California. For a full treatment of the topics raised here, see Ruth (2018).

$凶 \quad$ Matthias Ruth

matthias.ruth@ualberta.ca

1 Office of the Vice-President (Research) and Department of Economics, University of Alberta, Edmonton, AB T6G 2G7, Canada 
policy are most directly felt. Conversely, in times of deficient national political and economic leadership, considerable opportunities may arise for decision makers at the regional scale to counteract undesirable national developments and to put in place strategies that are fine-tuned to the region's conditions.

A corollary of this second set of values that stems from a regional perspective is that diversity in regional approaches to social and economic policy and investment create a database of natural experiments that may ultimately inform policy and investments at larger scales. The word database is used here in both a literal and figurative sense. It refers to the many observable outcomes associated with individual, independent, region-specific investments and policies. These outcomes can often be quantified, then analyzed, and generalized. It also refers to the collective experiences that are shaped by observing what works where and why.

Regional science is rich in methods and approaches tailored to harness the information generated at regional scales. In recent years, it has led to considerable advances in space-time analysis, management of highly heterogeneous and big data, and visualization of both the micro- and macro-phenomena mentioned above. Being able to effectively make apparent and harness the information embedded in data requires systematic analysis guided by theory. Here, too, the field has contributed to the understanding of social and economic dynamics by seeing what happens on the ground as an articulation of the fundamental mechanisms that are at work in the background. Many of the early conceptualizations of location theory or diffusion models, for example, are relevant still today.

In short, there is great power in choosing a regional perspective on social and economic processes. But with great power comes great responsibility. By its very definition, a focus on a smaller subset of a larger system is prone to relegating to the sidelines, or even disregarding, constraints imposed from the outside. Knowing what these constraints are, and how to operate at a regional scale within them, is a precondition for regions to flourish and to contribute to the sustainability of the larger systems within which they operate. Being able to retain a regional focus in the analysis, while bringing just enough external context to the endeavor, is not just a craft but also an art. The following section looks from the region beyond the boundaries to explore the role of fundamental constraints that will be binding in the long run. From that I then turn to the implications for theory, empirical application, and policy. I will then close my comments with reflections on the culture of regional science within which that art and craft are fostered.

\section{Boundary constraints for regional development}

A wide range of boundary constraints impact regional development-socioeconomic and political changes outside the region that lead to migration flows, for example, or technological and institutional changes over which the region has no influence but to which it must respond, such as the sectoral shifts from manufacturing to services observed in the last century, or more recent changes in transportation and communication technologies that fundamentally redefined the notion of a region in the first place. Two other constraints are of more immediate concern to me here in this presidential 
address - namely the resource constraints that are associated with limited availability of materials and energy and the limited waste assimilation capacities of the larger biosphere in which any economy and society are fundamentally embedded.

Although it may seem trivial to mention that any economy is part of a social system, which in turn is part of the ecosystem, much of modern economics has treated the three as separated. The traditional circular flow model in which value is exchanged among households, firms and financial institutions, for example, is devoid of any recognition that the economy cannot work as a perpetual motion machine. Resources are extracted from and wastes are released into an infinite environment that operates as a black box in the background of social and economic processes. Social inputs beyond labor costs are rarely, if ever, considered.

The implications of the economy as a wholly owned subsidiary of the biosphere are much more fundamental and far-reaching. The economy cannot take on a life of its own without the social context within which it operates. The socioeconomic system, in turn, cannot grow beyond biophysical boundaries. There is no such thing as sustainable growth.

None of this is new, of course. For example, the nineteenth-century British philosopher and civil servant, John Stuart Mill, eloquently pointed at the limits to economic expansion within a finite biosphere and argued that unlimited economic growth will result in the destruction of the environment and a reduction in the quality of life (Mill 1848). Yet, the almost exclusive focus of regional science on regional economic and population growth remains remarkably divorced from these fundamental insights. Because any region can often easily exchange materials, energy and waste products with other regions, environmental constraints are not perceived as binding. Efforts to boost growth locally then aggregate to unsustainable growth at the macroscale.

The lack of progress on curtailing material use, energy use and emissions to fall within biophysical limits can be deeply depressing - especially when regional science remains blind to these limits, and when it continues to perpetuate markets and economic growth as the solution to problems that are created by markets and economic growth. When regions export the problems they generate in order to continue their progress, explicit accounting should happen for the damages done elsewhere. Similarly, the benefits generated for one region by choosing improved practices in another will need to become an explicit part of the calculus by which decisions are made.

There is a rich set of analyses emerging on conditions that will retain or improve quality of life without having to perpetually increase economic output, and thus resource use and waste generation. Collectively referred to as "no growth economics," these analyses begin with the understanding that GDP and equivalent measures of output are utterly inadequate in reflecting quality of life, at least for developed nations (see, e.g., Victor 2008). Most strategies to promote true development-rather than growth-have a small energy and material footprint. Regional science has yet to offer a comprehensive set of theories, methods and tools that can be used to promote such strategies at regional scales without undermining the social and environmental conditions that generate welfare. 


\section{Analytical implications of boundaries for regional science}

\subsection{The limited value of prices as signals for decision making}

A hallmark of regional science lies in the recognition that human behavior is guided by incentives and that proper design of incentive systems can steer behaviors toward desirable outcomes. Well-functioning markets may give the signals on which to act—rising prices would suggest that the scarcity of a resource is increasing and thus stimulate a decline in the quantity demanded and a search for alternatives. Where unintended consequences of production and consumption are encountered, externalities may be internalized to adjust prices and the signals they give to change behaviors and technologies. But what if the world is more complex than presumed here? What if prices are not only the product of rational economic decision making and instead reflect deepseated social tensions and long-overlooked environmental constraints? For example, in societies in which women and children hold limited rights for self-expression and self-determination, the wages paid to them for their labor will be depressed. In places where environmental standards are low, resource extraction and environmental pollution may cause harms that remain unaccounted for in economic decision making. The prices of goods and services in conditions of social and environmental exploitation are then not worth much with respect to their ability to guide economic decisions toward optimal outcomes (Røpke 1999). More likely, they will entrench unsustainable practices. ${ }^{1}$

\subsection{The limited relevance of optimality}

The concept of optimality, as normally conceived in economic analysis, makes little sense from a complex systems perspective (van den Bergh and Stagl 2003). It has long been shown that humans, characterized by emotions and limited cognitive abilities, faced with decisions in a world of nonlinear and lagged relationships between actions and outcomes, and operating within a set of nested hierarchies-firms and households being part of a larger social system, which in turn operates within regional and global constraints - have a hard time making decisions that are optimal at any given point in time, let alone optimal across long time horizons or broad geographies. And if decisions need to be made by a community of humans with conflicting interests and aspirations - whether to grant permission for a social housing project, finance the expansion of a road, allow the closure of a hospital preserve a wetland near-by, ...- then the traditional notion of optimality is even less useful as a guiding principle or yardstick for the assessment of their actions.

If optimality is passé as a guiding principle in such settings, then what may take its place? At a minimum, decision making will need to recognize that there are always multiple criteria by which performance must be assessed, and multiple objectives must be pursued at any given point in time to meet the different objectives of members in the community. Multi-criteria, multi-objective decision making is far from new, and

\footnotetext{
${ }^{1}$ For a behavioral economics perspectives on violations of many standard economics assumptions, see, for example, DellaVigna (2009).
} 
has gradually made inroads into debates about, for example, choices of technologies, developments of infrastructures, and social and environmental policies (see, for example, Mirzaee et al. in press).

\section{Empirical implications of boundaries for regional science}

The traditional mantra in economic policy is for growth in output to stimulate wealth. That wealth, in turn, is expected to generate happiness and the financial and technological wherewithal to overcome any adverse impacts that economic growth has on society and the environment. Growth comes from using more inputs into the production process, which helps generate more output, and from increasing the productivity at which inputs are used.

In regional science, as elsewhere, much credence has been given to the role of technology change in shaping economic performance. But even the advent of a fundamentally new and much more efficient technology will have only slowly rising impact on aggregate productivity. Because the capital stocks in capital-intensive operations, and large-scale infrastructure systems in general, turn over only incrementally, the efficiencies at which they use materials and energy change only slowly. Accordingly, industrial and country-level emissions profiles are relatively steady for long periods of time, and today's capital stock casts a long environmental performance shadow into the future.

The more substantive limitations on environmental quality can be readily illustrated with what has been termed the Environmental Kuznets Curve, which purports to characterize the relationship between pollution levels and income: pollution levels increase with income, but some threshold of income will eventually be reached, beyond which pollution levels will decrease (Grossman and Krueger 1995). The underlying mechanisms behind the EKC presume that environmental quality is a normal good, demand for which increases as income increases. Economies of scale, resource-saving technological change in the extractive and manufacturing sectors, trade liberalization leading to "out-migration" of dirty processes, and development of regulatory mechanisms and institutions to stimulate environmental protection, are all seen to contribute to a country's improved environmental performance as economic development takes place.

Aside from the fact that the bulk of empirical work on Environmental Kuznets Curves is deeply flawed (Franklin and Ruth 2011), the built-in assumption that resource-intensive production can be moved from any region of interest to another obviously means that some regions will at some point in time run out of that option to improve their own performance. Similarly, given the physical limits on material and energy conversion processes means that previous rates of efficiency improvements must slow down. In short, two of the most fundamental drivers behind any perceived Environmental Kuznets Curve behavior will be less relevant in the future. Economic growth will then overwhelm any advancement in environmental performance.

Regional science owes it to those who make long-term investment and policy decisions to alert them to the shortcomings of current practices, and to help identify alternative development paths. 


\section{Policy implications of boundaries for regional science}

Let me provide in this section two specific illustrations on what it would mean to do regional science in a way that (a) incorporates in its models and approaches explicitly some insights into the boundary conditions under which regions must operate, (b) acknowledges the heterogeneity of regional actors and their social and economic conditions, (c) makes good sense in light of fundamental uncertainties and surprises, and thus (d) helps identify robust — rather than conventionally perceived optimalsolutions to regional challenges. The first of these illustrations concerns the notion of co-benefits and co-costs of economic activity, and the second explicitly deals with the cost of inaction.

\subsection{Co-benefits and co-costs}

Policies are typically designed and investment decisions are implemented to address specific, well-described issues-be it to reduce, for example, traffic congestion or cut emissions of greenhouse gases into the atmosphere. Besides intended impacts, there are two related aspects that can have far-reaching implications for policy and investment making - the ancillary cost and benefit impacts of any action, and the indeterminacy of causal relationships between system interventions and outcomes.

It is the rule rather than the exception that policies and investments generate cobenefits and co-costs, and since their magnitude may ultimately sway a decision, they must be reflected in policy and investment analysis ( $\mathrm{Ng} \mathrm{1983).} \mathrm{The} \mathrm{generation} \mathrm{of} \mathrm{envi-}$ ronmental and health benefits that accrue, for example by reducing traffic congestion or curbing emissions from power generation, may in the end be the dominant outcome compared to the stated goal of improving the flow of transportation or of stabilizing the climate. The choice of production methods in one region may improve its environmental conditions but do so at the expense of other regions, generating for them a host of social, economic and environmental co-costs, or it could improve conditions elsewhere, and thus generate co-benefits, all of which would ideally be incorporated in research and regional economic decision making.

Total ancillary benefits or costs may exceed primary benefits or costs (Pearce 2000), and even where they do not, their inclusion may help magnify the primary benefits and costs (Ekins 1996) and can alter the rank-ordering of preferred policy choices (Aunan et al. 2004). Inclusion of co-benefits and co-costs thus adds complexity to any cost-benefit comparison and poses challenges for decision making and implementation, as well as institutional arrangements for them both.

\subsection{Cost of inaction}

Major investment and policy challenge typically entail considerable cost. However, for any investment and policy action there are also significant costs of inaction, many of which typically do not enter the decision-making process, in part because the costs of inaction are often unknown, diffuse and thus more easily shared across society, while, in contrast, costs of action are localized, their estimates are anchored on features of 
known technologies and approaches, and their impacts include reduced profits and other forms of privatized gains among identifiable players in the marketplace. In such an environment, policy and investment decisions tend to be made with respect to the known cost of action. Making an "optimal decision" then means finding an outcome that minimizes the opportunity cost associated with the known and readily quantified cost of action.

Estimates of the costs of adapting environmental and infrastructure systems and services to climate change, for example, can provide insight into the very real costs of inaction, or conversely, the benefits of maintaining and protecting societal goods and services. Since it is typically at the sectoral and regional levels where those costs are borne and benefits are received, cost of inaction estimates can provide powerful means for galvanizing the discussion about climate change policy and investment decision making. Providing such estimates may also help break the log-jam that so often is present when only the cost of action, at fixed budgets, is considered.

Cost estimates may understate impacts on the economy and society to the extent that they simply cover what can be readily captured in monetary terms. The broader impacts on the social fabric, long-term economic competitiveness of regions and nations, changes in environmental quality, and quality of life, largely are outside the purview of typical analyses, yet likely not trivial at all. Together, the monetary and non-monetary, direct, indirect and induced costs on society and the economy provide a strong basis on which to justify actions to mitigate and adapt to climate change.

Arriving at cost of inaction estimates for education policies, public transportation and any other intervention in the regional social and economic fabric requires broadbased understanding of local conditions and how they are shaped by larger dynamics. Regional science is well poised to draw on relevant regional insights and to develop comprehensive models and analyses that broaden the basis on which decisions are made to include the cost of inaction.

\section{On the culture of regional science in a resource-constrained world}

The impressive arsenal of theories, models and approaches in regional science that were developed since the late 1940s exhibits considerable sophistication and rigor that are a clear strength of the field. During times of rapid global and regional economic growth and development, the focus of regional science was naturally different from what is expected today. The complexity of regional challenges, the tighter interdependencies of social, economic and environmental processes at the regional scale, and the increasingly binding global interconnections and constraints on regional performance call for enlarging the tool box of regional science in ways that maintain its relevance in the twenty-first century. To do so may require innovation along several frontiers. There must be continued innovation in the methods deployed by regional scientists-not just ever more sophisticated refinements of twentieth century economics, for example, but entirely new approaches that bring into the fold an understanding of the social and environmental constraints on regional economic performance, that are calibrated to a world full of novelty and surprise, and that allow for 
knowledge discovery through experimentation rather than analysis that is agnostic of policy and investment implications or merely prescriptive.

One way to ensure the relevance of the field for the future is to enrich the diversity of the people engaged in it. A regional science that reflects through its regional, national and international societies the diversity of the places for which it is relevant already is well poised to remain relevant. Similarly, much like the social and economic vibrancy of regions, the field of regional science benefits from diversity across the demographic spectrum. And if the field is keen on making sure that regional science helps not only understand and promote the conditions for individual regions to flourish, but for them to collectively contribute to the sustainability of the human enterprise, then diversity of insights into the social and environmental conditions that generate opportunities and constraints will be essential.

Acknowledgements Many thanks go to Geoffrey Hewings for his insightful comments on the address, and his steadfast support and friendship over the decades.

\section{References}

Aunan K, Fang J, Vennemo H, Oye K, Seip HM (2004) Co-benefits of climate policy-lessons learned from a study in Shanxi, China. Energy Policy 32:567-581

DellaVigna S (2009) Psychology and economics: evidence from the field. J Econ Lit 47(2):315-372

Ekins P (1996) How large a carbon tax is justified by the secondary benefits of $\mathrm{CO}_{2}$ abatement? Resour Energy Econ 18:161-187

Franklin RS, Ruth M (2011) Growing up and cleaning up: the environmental kuznets curve redux. J Appl Geogr 32:29-39

Grossman GM, Krueger AB (1995) Economic growth and the environment. Q J Econ 110:353-377

Mill JS (1848) Principles of political economy with some of their applications to social philosophy. John W. Parker, London

Mirzaee S, Ruth M, Fannon D (2019) Reconciling diverse perspectives of decision makers on resilience and sustainability. In: Ruth M, Reisemann SG (eds) Resilience of socio-technical systems. Edward Elgar, Cheltenham (in press)

Ng Y-K (1983) Welfare economics: introduction and development of basic concepts, revised edn. Macmillan, Basingstoke

Pearce D (2000) Policy frameworks for the ancillary benefits of climate change policies. In: OECD (ed) Assessing the ancillary benefits and costs of greenhouse gas mitigation. OECD, Paris, pp 517-560

Røpke I (1999) Prices are not worth much. Ecol Econ 29(1):45-46

Ruth M (2018) Advanced introduction to ecological economics. Edward Elgar, Cheltenham

van den Bergh JJC, Stagl S (2003) Coevolution of economic behaviour and institutions: towards a theory of institutional change. J Evol Econ 13(3):289-317

Victor PA (2008) Managing without growth: slower by design, not disaster. Edward Elgar, Cheltenham 